\title{
POR QUE O EXPRESSIVISMO PURO NÃO FUNCIONA PARA INJÚRIAS?
}

\author{
Rogério Corrêa ${ }^{1}$ \\ Universidade Federal de Santa Maria
}

Resumo: 0 expressivismo puro divide as expressões entre as que possuem apenas conteúdo descritivo e as que possuem apenas conteúdo expressivo. As primeiras, mas não as segundas, são aptas à verdade e à falsidade. Hedger aplica esta distinção às injúrias e, como resultado, elas são consideradas termos com conteúdo puramente expressivo. 0 seu argumento geral baseia-se no teste de projeção de comportamento de injúrias e em quatro evidências. Nesse sentido, se é verdade que injúrias raciais não são expressões com conteúdo puramente descritivo, então, elas são expressões com conteúdo puramente expressivo. É verdade que injúrias raciais não são expressões com conteúdo puramente descritivo. Portanto, elas são expressões com conteúdo puramente expressivo. Neste artigo, apresento um contraexemplo à tese expressivista pura. Desse modo, argumento que não é o caso que injúrias são semanticamente diferentes de termos descritivos, pois elas são analisáveis semanticamente.

Palavras-chave: pejorativos, expressivismo, injúria racial, injúria sexual, semântica.

\begin{abstract}
Abstrtact: Pure expressivism divides expressions between those that have only descriptive content and those that have only expressive content. The former, but not the latter, are apt to truth and falsehood. Hedger applies this distinction to slurs, and as result, they are considered terms with purely expressive content. His general argument is based in the projection behaviors of slurs and four evidences. In this sense, if it is true that racial slurs are not purely descriptive expressions, then they are expressions with purely expressive content. It is true that racial slurs are not purely descriptive expressions. Therefore, they are expressions with purely expressive content. In this paper, I present a counterexample to the pure expressivist thesis. Thus, I argue it is not the case that slurs are semantically different from descriptive terms, since they are semantically analyzable.
\end{abstract}

Keywords: pejoratives, expressivism, racial slur, sexual slur, semantics.

\section{Introdução}

Tradicionalmente, o expressivismo foi concebido como um tipo de não cognitivismo acerca da linguagem moral ${ }^{2}$. Para o não cognitivismo, frases morais são peculiares, pois não são verdadeiras nem falsas, uma vez que não descrevem o mundo tal como o fazem as frases descritivas. Desse modo, o não cognitivismo sustenta a tese inversa do cognitivismo. O emotivismo de Ayer (1936) e Stevenson (1963) e o prescritivismo de Hare (1952) são concepções não cognitivistas da linguagem moral. $\mathrm{O}$ expressivismo atual, no entanto, é um pouco diferente, pois ele não diz respeito à linguagem moral,

\footnotetext{
1 E-mail para contato: rogerio.fsc@ufsm.br

2 SCHROEDER, 2008, p.3-4.

(C) Dissertatio - Volume Suplementar 6, Fevereiro - 2018
} 
mas ao pensamento moral. Se o ponto central não é a linguagem moral, mas o pensamento moral, segue-se que a diferença entre a linguagem moral e a linguagem descritiva é derivada da diferença entre o pensamento moral e o pensamento descritivo. Portanto, frases morais, mas não frases descritivas, expressam estados não cognitivos da mente, tais como desejo, raiva e coisas desse tipo. Como frases morais são expressões de estados não cognitivos e eles não são aptos à verdade e à falsidade, então, elas também não são aptas à verdade ou à falsidade.

O emotivismo de Ayer é um bom exemplo de teoria para a qual é impossível atribuir um valor de verdade a frases morais. Nesse sentido:

[...] if I say to someone, 'you acted wrongly in stealing that money', I am not stating anything more than if I simply said, 'you stole that money'. In adding that this action is wrong, I am not making any further statement about it. I am simply evincing my moral disapproval of it. It is as if I had said, 'You stole that money', in a particular tone of horror, or written it with the addition of some special exclamation marks. The tone, or the exclamation marks, adds nothing to the literal meaning of the sentence. It merely serves to show that the expression of it is attended by certain feelings in the speaker ${ }^{3}$.

De acordo com a passagem anterior, frases morais negativas revelam ou expressam uma reprovação do falante, isto é, expressam um sentimento ou estado não cognitivo. Como estados não cognitivos não são aptos à verdade e à falsidade, pois não descrevem algo no mundo, segue-se que frases morais negativas não são aptas à verdade e à falsidade também. $\mathrm{O}$ mesmo pode ser dito sobre frases morais positivas, pois elas expressam sentimentos positivos por parte do falante, como, por exemplo, aprovação.

O expressivismo está presente no recente debate sobre pejorativos. Nesse debate, ele não ocorre como uma teoria moral, mas como uma teoria sobre o significado dos termos pejorativos. Denomino de pejorativos o conjunto de expressões formado por palavrões, ofensas e injúrias (raciais, sexuais e religiosas $)^{4}$. A tese geral expressivista sustenta que frases contendo termos pejorativos expressam um sentimento por parte do falante. Se eu

${ }^{3}$ AYER, 1936, p.110.

${ }^{4}$ Minha caracterização difere da de Hedger, pois sua discussão gira em torno de injúrias raciais, sexuais e palavrões. Portanto, ela não inclui ofensas nem as considera como constituintes do conjunto dos pejorativos. Do meu ponto de vista, porém, injúrias, palavrões e ofensas constituem ou são subconjuntos dos pejorativos. Usarei pejorativos ao longo do texto, mas o leitor deve ter claro que Hedger não faz nenhuma afirmação sobre as ofensas como um tipo de pejorativo. É verdade que ele fala sobre a ofensa. No entanto, ele a considera como uma característica ou propriedade das injúrias e palavrões. Mais adiante, distingo entre depreciar e ofender como características dos pejorativos. 
chamo o meu vizinho de viado 5 , por exemplo, uso uma injúria sexual para depreciá-lo. Para casos assim, a tese expressivista soa como algo do tipo 'where $\mathrm{D}$ is a derogatory word and $\mathrm{N}$ its neutral counterpart, someone who predicates $\mathrm{D}$ of $\mathrm{x}$, (i) says that $\mathrm{x}$ is $\mathrm{N}$, and (ii) condemns those who are $\mathrm{N}^{\prime}$. A expressão 'viado', com a qual deprecio o meu vizinho homossexual, revela um sentimento meu para com ele que tanto pode ser de reprovação, raiva, quanto qualquer outro tipo de sentimento negativo para com o fato dele ser homossexual. Dado que o conteúdo expressivo de "viado" não contribui para as condições de verdade da frase que enuncio, pois expressa um estado não cognitivo, segue-se que a frase "Meu vizinho é viado" não pode ser verdadeira nem falsa. Logo, ela simplesmente revela a minha reprovação.

Hedger (2012) propõe uma defesa expressivista dos pejorativos. Não se trata exatamente dos pejorativos, mas das injúrias e dos palavrões. A sua posição, porém, necessita de uma qualificação adicional, pois ela não é estritamente expressivista, mas expressivista pura. Existem outras propostas expressivistas que podem ser consideradas híbridas, uma vez que associam a tese expressivista com outras abordagens ${ }^{7}$. Potts ${ }^{8}$, por exemplo, propõe um expressivismo híbrido, uma vez que sustenta que pejorativos são expressões com conteúdo expressivo analisáveis quando consideradas como implicaturas convencionais. Hedger, como mostrou $\mathrm{Croom}^{9}$, assume a distinção, largamente discutida na literatura ${ }^{10}$, entre expressões com conteúdo puramente descritivo e expressões com conteúdo puramente expressivo. No grupo dos pejorativos, distingue dois subgrupos, um que contém expressões com conteúdo puramente expressivo e outro que contém expressões com conteúdo puramente descritivo. Deve-se observar que Hedger não enumera exaustivamente termos para um e outro subgrupo e tampouco apresenta argumentos para essa distinção, mas assume que "asshole" tem conteúdo descritivo, enquanto "fucker" tem conteúdo expressivo. Além disso, a atribuição de caráter expressivo a determinado subgrupo de pejorativos é derivada de sua análise do palavrão "fucker" r"11. Esse aspecto, inclusive, é fundamental para as críticas que Croom faz ao expressivismo puro de Hedger.

${ }^{5}$ A grafia correta é veado, mas escrevo viado para manter mais próximo do modo como se fala no português.

${ }^{6} \mathrm{HOM}, 2010$, p.171.

7 WHITING 2007 e 2013; BOISVERT 2008; SCHRODER 2009; MCCREADY 2010; CROOM 2014 e 2014; GUTZMANN 2011; HAY 2011.

8 Em seus trabalhos de 2003; 2005; 2007 e 2012.

${ }^{9} 2014$ p.230.

10 KAPLAN 1999; POTTS 2003 e KRATZER 1999.

11 CROOM, 2014 p.229. 
De qualquer maneira, dessa distinção segue-se que "asshole" acompanha termos como "leão", "carro" e "casa", enquanto "fucker" acompanha termos como "slue", "nigger", "ai" e "ops"12. Esses últimos são muito peculiares, visto que consistem em típicos exemplos de partículas expletivas que funcionam como recursos linguísticos para o falante expressar sentimentos. Se vou pagar minhas compras no mercado e percebo que esqueci minha carteira em casa, posso dizer "Ai! Esqueci a minha carteira em casa" ou "Ai! Droga! Esqueci a minha carteira em casa" para externar minha raiva ou frustração. Aqui, o ponto fundamental é que termos com conteúdo meramente expressivo não são aptos à verdade e à falsidade.

A estratégia argumentativa de Hedger, segundo $\mathrm{Croom}^{13}$, é desenvolvida em dois momentos. No primeiro, ele sustenta que injúrias raciais não são expressões com conteúdo puramente descritivo. Aqui, o teste de projeção de comportamento é central e o seu argumento pode ser sintetizado em uma modus ponnens. Se a projeção de comportamento das injúrias difere da projeção de comportamento das expressões com conteúdo puramente descritivo, então, elas são semanticamente diferentes. A projeção de comportamento das injúrias difere da projeção de comportamento de expressões descritivas. Portanto, elas são semanticamente diferentes. Por semanticamente diferentes, entenda-se que injúrias não contribuem para $o$ valor de verdade das frases em que elas ocorrem, ao passo que as expressões descritivas, sim. No segundo momento, Hedger sustenta que injúrias são expressões com conteúdo puramente expressivo. Para tanto, ele fornece quatro evidências. A primeira delas é baseada na tradução de palavrões do espanhol para o inglês. A segunda assenta-se na enunciação de um palavrão. A terceira baseia-se na falta de argumentos contra alguém que profere uma injúria. A quarta e última é centrada na enunciação de uma injúria racial típica para depreciar afrodescendentes dirigida para um homem branco de nacionalidade sueca. Creio, desse modo, que o argumento geral do expressivismo puro é o seguinte: se é verdade que injúrias raciais não são expressões com conteúdo puramente descritivo, então, elas são expressões com conteúdo puramente expressivo. É verdade que injúrias raciais não são expressões com conteúdo puramente descritivo. Portanto, elas são expressões com conteúdo puramente expressivo.

O meu objetivo neste artigo é fornecer um contra-argumento ao expressivismo puro. Nesse ponto, concordo com Croom (2014) que também

12 Quando refiro-me à expressão, escrevo termo viado ou "viado".

132014 , p.230. 
apresentou razões contra o expressivismo puro. No entanto, diferentemente de Croom, não fornecerei argumentos com base em evidências empíricas. A minha estratégia consiste em mostrar que o consequente do argumento geral do expressivismo puro é falso. Para tanto, forneço uma análise semântica de duas frases contendo injúrias, ou seja, mostro que injúrias não são apenas expressivas, pois são analisáveis semanticamente. Se minha análise semântica está correta, o meu contra-argumento assume a seguinte forma: se é verdade que injúrias não são expressões com conteúdo puramente descritivo, então, elas são expressões com conteúdo puramente expressivo. É verdade que injúrias não são expressões com conteúdo puramente descritivo, portanto, elas são expressões com conteúdo puramente expressivo. Porém, não é o caso que injúrias são expressões com conteúdo puramente expressivo, uma vez que elas são analisáveis semanticamente e, para serem analisáveis semanticamente, elas devem possuir conteúdo semântico. Logo, não é o caso que injúrias não são expressões com conteúdo puramente descritivo. No que se segue, primeiro, caracterizo o expressivismo puro, depois, apresento algumas das críticas de Croom ao expressivismo puro de Hedger e, por último, apresento a minha análise semântica de dois pejorativos. Usarei como exemplos uma injúria racial e uma injúria sexual.

\section{O expressivismo puro para injúrias}

O objetivo básico de Hedger é reforçar a distinção entre expressões que têm apenas conteúdo descritivo e aquelas que têm apenas conteúdo expressivo e, consequentemente, caracterizar um subgrupo de pejorativos como contendo apenas termos do último tipo". Considere as frases "Paulo é educado" e "Paulo é cortês"15. Dadas as frases, posso inferir uma da outra validamente. O mesmo não ocorre com "Paulo foi promovido" e "O viado do Paulo foi promovido". Posso obter a primeira a partir da segunda validamente, mas o inverso não. A diferença entre os dois exemplos é que, no caso de "Paulo é educado" e "Paulo é cortês", as frases envolvidas são sinônimas e nada mais. No segundo caso, as frases são sinônimas, mas há um plus. $\mathrm{O}$ elemento adicional fica por conta da presença do termo "viado" em "O viado do Paulo foi promovido". O que esse termo carrega a mais é a atitude depreciativa do falante em relação a Paulo. Portanto, "Paulo foi promovido" não revela uma atitude depreciativa do falante para com Paulo, mas "O viado do Paulo foi promovido", sim.

14 2012, p.76.

${ }^{15}$ Esses casos são adaptados a partir dos exemplos de Hedger (2012, p.76). 
A diferença mencionada anteriormente é reforçada e explicada pelo teste de projeção de comportamento ${ }^{16}$. De acordo com o teste, um termo depreciativo permanece depreciativo mesmo que ele esteja "embedded under negation, as the antecedent of a conditional, in a question, etc" 17 . Desse modo, se uma expressão passa no teste de projeção, isto é, se o seu caráter depreciativo não é alterado em nenhuma das situações propostas, segue-se que ela é expressiva, pois é isso que as condições propostas pelo teste estabelecem. Dito de outra forma, se aplico algum dos procedimentos que compõem o teste de projeção de comportamento a uma expressão depreciativa e ela não perde o seu caráter depreciativo, então, provo que esse caráter não se relaciona com o conteúdo semântico da expressão, mas com o conteúdo expressivo. Em última instância, provo que tem a ver com o falante. Considere, como primeiro exemplo, a ocorrência de um termo depreciativo no escopo da negação. $\mathrm{Na}$ frase "Não é o caso que Paulo é viado", o termo "viado" permanece depreciativo ainda que ele ocorra no escopo da negação. O mesmo acontece quando digo "Se o viado do Paulo foi promovido, então Paulo foi promovido". Aqui, "viado" permanece depreciativo a despeito de ocorrer no escopo do antecedente do condicional. Por que, porém, a projeção de comportamento é importante? Basicamente, porque ela coloca um problema para teorias semânticas sobre pejorativos.

$\mathrm{O}$ teste de projeção de comportamento mostra que o caráter depreciativo de um termo não diz respeito ao seu conteúdo semântico, mas ao falante. Considere a frase "Paulo é inteligente". Para certa teoria semântica, a extensão de "Paulo" é um indivíduo particular e a proposição expressa pela frase "Paulo é inteligente" predica ou atribui o predicado "ser inteligente" a Paulo. Se Paulo for inteligente de fato, a frase será verdadeira; caso, contrário, será falsa. Desse modo, a extensão de "Paulo é inteligente" será um valor de verdade, isto é, ou o verdadeiro ou o falso ${ }^{18}$. Considere, agora, a frase "Paulo é inteligente e Canadá é frio". Se afirmo essa frase, então, também afirmo a frase "Paulo é inteligente", pois a verdade de "Paulo é inteligente e Canadá é frio" depende da verdade de "Paulo é inteligente". Caso a frase seja outra, por exemplo, "Se Paulo é inteligente, então Joana também é inteligente", e eu afirmá-la, disso não se segue que afirmo "Paulo é inteligente", pois a verdade

16 POTTS 2007; HOM 2008, 2010 e 2012; WILLIAMSON 2009; MCCREADY 2010; CROOM 2011 e 2013; ANDERSON \& LEPORE 2013; HAY 2013; WHITING 2013.

17 HEDGER 2012, p.75.

18 Via de regra, as críticas dirigidas às abordagens semânticas miram teorias baseadas nesse modelo semântico, que eu chamo de modelo de inspiração freguiana. No entanto, ele não é o único modelo possível. O modelo que ofereço difere dele. Na falta de um nome melhor, denomino-o de modelo de satisfação. Ele é inspirado em Larson \& Segal (1995) e Schirmer (2010). 
de "Se Paulo é inteligente, então Joana também é inteligente" não depende da verdade de "Paulo é inteligente", uma vez que o condicional é verdadeiro no caso em que os seus dois componentes são falsos. O teste de projeção de comportamento mostra que frases com pejorativos não se comportam desse modo, haja vista que elas contêm um elemento adicional relativo ao sujeito que profere a frase. Uma frase pejorativa, como mostrei anteriormente, continua depreciativa, quando o pejorativo ocorre no escopo de uma negação ou de um condicional. A frase "Não é o caso que Paulo é viado" continua depreciativa a despeito de o pejorativo ocorrer no escopo da negação. Essa diferença não é explicada, do ponto de vista de uma teoria expressivista pura, com base no conteúdo semântico do termo depreciativo, mas a partir da distinção entre expressões com conteúdo puramente descritivo e expressões com conteúdo puramente expressivo. Desse modo, o caráter depreciativo de "viado", por exemplo, é uma função do falante e não do seu conteúdo semântico. Dada essa distinção, Hedger aplica-a aos pejorativos. Como resultado, ele obtém pejorativos que descrevem e pejorativos que expressam. É para esse último caso que ele fornece quatro evidências a favor.

O objetivo das quatro evidências é fornecer bases para um argumento cuja conclusão afirma que pejorativos têm apenas conteúdo expressivo. A primeira evidência é baseada em uma constatação. Segundo Hedger ${ }^{19}$, depois de aprender algumas palavras em espanhol, ele constatou que diferentes dicionários fornecem diferentes expressões em inglês como tradução para essas palavras. No entanto, um número significativo de termos depreciativos, em especial os mais ofensivos ${ }^{20}$, não diferem de significado. Isso acontece porque eles têm o mesmo conteúdo expressivo, mas carecem de conteúdo descritivo. A segunda evidência é a constatação de que se estou lavando o meu carro e encontro uma sujeira quase no final da limpeza, expresso minha frustração com a expressão "Merda!" 21 . Essa expressão não descreve um estado de coisas, mas apenas e simplesmente revela minha frustração ou raiva. A terceira evidência recorre à falta de bases para argumentar contra quem profere um pejorativo 22 . Se digo que o meu vizinho é viado, ninguém tem como argumentar contra a minha afirmação, pois a frase "O meu vizinho é viado” não é uma descrição do meu vizinho. Em contrapartida, se digo que o

192012 , p.77.

20 Mantenho, aqui, a ofensa como uma característica dos pejorativos, pois estou descrevendo a posição de Hedger. No entanto, considero ofensas termos como "imbecil" e "idiota". Portanto, eles compõem um subgrupo dos pejorativos. Nesse sentido, eles podem ofender e depreciar.

${ }^{21} 2012$, p.77.

22 Não sei o porquê, mas Croom (2014) não considera isso como uma evidência. 
meu vizinho é mecânico, quando ele não é mecânico, mas marceneiro, qualquer um poderá contra argumentar, pois a frase " $\mathrm{O}$ meu vizinho é mecânico" é uma descrição falsa do meu vizinho. Uma última evidência sustenta que posso ofender um homem branco de origem sueca dirigindo-lhe um termo depreciativo usado para depreciar afrodescendentes ${ }^{23}$. Como essa pessoa sente-se ofendida, segue-se que não se trata apenas de um erro linguístico de minha parte, mas da expressão de algum sentimento negativo meu para com ela.

Creio que, dadas às evidências anteriores, o argumento geral a favor da existência de um subgrupo de pejorativos com conteúdos expressivos é o seguinte: existem expressões com conteúdo puramente expressivo e expressões com conteúdo puramente descritivo. No que diz respeito aos pejorativos, existem dois subgrupos. Um subgrupo com pejorativos que possuem apenas conteúdo descritivo e outro com conteúdo apenas expressivo. Isso é o caso, pois, (1) os dicionários de inglês fornecem diferentes expressões como tradução de palavrões do espanhol, que não diferem de significado. Essas expressões não diferem de significado porque elas têm o mesmo conteúdo expressivo; (2) se ao lavar o meu carro encontro uma sujeira quase no final do processo, expresso minha frustração com a expressão "Merda!", a qual não descreve um estado de coisas, mas apenas e simplesmente revela a minha frustração, (3) se digo que o meu vizinho é viado, ninguém tem como argumentar contra minha afirmação, dado que "viado" não é uma descrição do vizinho, mas a expressão de um sentimento meu para com ele. Em contrapartida, se digo que o meu vizinho é mecânico, qualquer um poderá contra argumentar, pois se trata de uma expressão descritiva falsa e (4) posso ofender um homem branco de origem sueca dirigindo-lhe um termo depreciativo típico para afrodescendentes. Como essa pessoa sente-se ofendida, segue-se que não se trata apenas de um erro linguístico de minha parte, mas a expressão de algum sentimento negativo meu em relação a ela. Com isso, Hedger pretende não apenas reforçar a distinção entre expressões com conteúdo puramente descritivo e expressões com conteúdo puramente expressivo, mas, além disso, mostrar que há uma subclasse de pejorativos que pertence ao último grupo. $\mathrm{Na}$ sequência, mostro as críticas que Croom formulou à tese de Hedger. 


\section{Argumentos contra o expressivismo puro}

A primeira crítica formulada por Croom identifica um pressuposto no argumento formulado com base na evidência da tradução de palavrões do espanhol ${ }^{24}$. Basicamente, o argumento afirma que palavrões do espanhol têm conteúdo expressivo, pois as suas traduções para o inglês mantêm os seus caráteres ofensivos. Se é assim, então, as injúrias também possuem apenas conteúdo expressivo. O erro, aqui, é considerar palavrões como equivalente a injúrias. Isso é um erro, pois linguisticamente eles não funcionam do mesmo modo. A fim de mostrar a diferença entre um e outro caso, Croom (2014, p. 232) propõe um teste de felicidade de pejorativos. Para tanto, considere a expressão " $[x]^{d /,}$ como uma variável que só pode ser substituída por expressões com conteúdo descritivo e considere dois grupos de frases.

O primeiro grupo formado por:

(1a) $T$ é um filho da puta, mas nego que estou dizendo qualquer coisa sobre a sua $[x]^{d}$. sua $[x]^{d}$.

(2a) T é um afro-brasileiro, mas nego que estou dizendo algo sobre a

e

(1b) Este filho da puta é meu colega, mas nego que estou dizendo algo sobre a sua $[x]^{d}$.

(2b) Este afro-brasileiro é meu colega, mas nego que estou dizendo algo sobre a sua $[x]^{d}$.

O segundo grupo formado por:

(1c) $T$ é um filho da puta, mas nego que estou dizendo algo sobre a sua [identidade racial].

(2c) $T$ é um afro-brasileiro, mas nego que estou dizendo algo sobre a sua [identidade racial]

e

(1d) Este filho da puta é meu colega, mas nego que estou dizendo algo sobre a sua [identidade racial].

(2d) Este afro-brasileiro é meu colega, mas nego que estou dizendo algo sobre a sua [identidade racial]

De acordo com o teste, se tento substituir os termos com conteúdo puramente descritivo, então a felicidade desses casos é bloqueada, mas o mesmo não ocorre com a felicidade dos casos em que se têm conteúdos puramente expressivos. Expresso em outros termos, os casos (2a) e (2b) têm a sua felicidade bloqueada, mas os casos (1a) e (1b) não, pois as substituições

242014, p.232. 
resultam em (1c), (2c), (1d) e (2d). Dessas, (2c) e (2d) são infelizes, pois, ao substituir-se a variável pelo termo "identidade racial" explicita-se que se trata de uma questão racial. Dito de outra maneira, mostro que estou tipificando o meu alvo em função de sua identidade racial. Injúrias, portanto, possuem uma função classificatória. No caso de (1c) e (1d), porém, o enunciado é feliz, uma vez que as características descritivas individuais de $T$ são irrelevantes para $o$ sujeito que profere a frase. Como o falante profere uma frase que revela um conteúdo emocional, ela não é apta à verdade e o falante pode chamar o seu alvo de filho da puta e negar que está descrevendo qualquer característica dele. Portanto, o seu enunciado é feliz. Consequentemente, o teste de felicidade mostra que palavrões e termos descritivos funcionam de modos diferentes. Agora, use uma injúria racial e uma injúria sexual, como, por exemplo, "macaco" e "viado". Desse modo, tem-se:

(1a) T é um filho da puta, mas nego que estou dizendo qualquer coisa sobre a sua $[x]^{d}$.

(1b) $T$ é um macaco, mas nego que estou dizendo qualquer coisa sobre a sua $[x]^{d}$.

(1c) $T$ é um viado, mas nego que estou dizendo qualquer coisa sobre a sua $[x]^{d}$.

(1a') T é um filho da puta, mas nego que estou dizendo qualquer coisa sobre a sua [identidade sexual/racial].

(1b’) $T$ é um macaco, mas nego que estou dizendo qualquer coisa sobre sua [identidade racial].

(1c') $T$ é um viado, mas nego que estou dizendo qualquer coisa sobre a sua [identidade sexual].

O que esses casos mostram é que a tese expressivista está correta para palavrões, mas não está correta para injúrias, pois (1a') não seleciona ou tipifica uma característica descritiva específica do seu alvo. Por isso, é um enunciado feliz. O mesmo não ocorre com (1b') e (1c'), pois, nesses casos, características descritivas específicas são selecionadas. No primeiro caso, uma característica racial, uma vez que o alvo do enunciado é tipificado em função de ser afrodescendente. No segundo caso, uma característica sexual, visto que o alvo é tipificado em função de ser homossexual. É por isso que são enunciados infelizes. Consequentemente, não funcionam do mesmo modo que palavrões. A conclusão geral de Croom, a partir desses casos, é que as injúrias selecionam características descritivas dos seus alvos que dizem respeito à raça, à orientação sexual, à classe, à nacionalidade, à religião, ao gênero, à orientação sexual, entre 
outras $^{25}$. Palavrões e demais termos expressivos, porém, além de não selecionarem os seus alvos desse modo, não possuem diferenças entre si quanto ao conteúdo descritivo, simplesmente, porque não possuem conteúdo descritivo.

No caso do segundo argumento de Hedger, baseado na evidência de alguém que xinga o carro, Croom afirma que ele sofre do mesmo erro do anterior. Ambos pressupõem que injúrias funcionam do mesmo modo que palavrões. Desse modo, como palavrões não descrevem os seus alvos, injúrias também não descrevem. Para reforçar o caráter inadequado da tese expressivista, Croom fornece o seguinte argumento: se palavrões e injúrias raciais são termos de mesmo tipo e se ninguém em particular tende a sentir-se atingido por um palavrão, segue-se que ninguém em particular tende a sentir-se atingido por uma injúria racial ${ }^{26}$. Expresso de outra forma, se chamo alguém de filho da puta e essa pessoa não tende a sentir-se atingida pelo palavrão, então o mesmo deve ocorrer se chamo o meu vizinho afrodescendente de macaco, pois injúrias funcionam do mesmo modo que palavrões. Se isso é verdade, o expressivismo puro é obrigado a sustentar que frases com injúrias são empiricamente falsas. Mais do que isso, o expressivismo puro deve sustentar que ninguém em particular deve sentir-se atingido por uma injúria, pois ela carece de conteúdo descritivo e apenas expressa um estado não cognitivo de quem a profere. Portanto, o expressivismo compromete-se com a tese de que se alguém, o meu vizinho afrodescendente, por exemplo, sente-se atingido por uma injúria, ele sente-se injuriado sem razão.

Por último, há o argumento com base na evidência de que um homem branco sueco pode sentir-se ofendido por uma injúria típica destinada a afrodescendentes. Dado que não apenas afro-brasileiros consideram macaco ofensivo, mas suecos também, segue-se que injúrias raciais geralmente são ofensivas para qualquer um. Além disso, dado que injúrias são ofensivas para quem quer que seja, elas são puramente expressivas. O problema com essa tese é que ela confunde ser alvo de um ato potencialmente ofensivo com ser vítima de um ato potencialmente ofensivo. Chamar o meu vizinho afro-brasileiro de macaco não é a mesma coisa que chamar o meu outro vizinho sueco de macaco. O primeiro é vítima de um ato ofensivo, mas o segundo, não. Nesse aspecto, concordo com a distinção feita por Hom, a qual ajuda a esclarecer o ponto em questão ${ }^{27}$. Há uma diferença de natureza entre expressões depreciativas e ofensivas. As primeiras são objetivas e dizem respeito às

${ }_{25}$ CROOM, 2014, p.233.

262014 , p.234.

272012 , p. 402. 
condições de verdade das frases em que ocorrem. As segundas não são objetivas, mas subjetivas. Portanto, não dizem respeito às condições de verdade das frases em que ocorrem. Quando xingo o meu vizinho de macaco, há uma dimensão objetiva envolvida, dado que o tipifico em função da sua condição racial ou de gênero, caso xingue-o de viado, por exemplo. Quando chamo o meu vizinho de bunda mole, não o tipifico em função de uma característica em particular. Creio, no entanto, que essa explicação de Hom pode ser modificada, pois, do meu ponto de vista, tanto palavrões quanto injúrias e ofensas são analisáveis semanticamente. Isso significa que as frases em que elas ocorrem tanto podem ser verdadeiras quanto falsas. O caráter depreciativo não é algo intrínseco às expressões, mas derivado das instituições sociais ${ }^{28}$. Pense, por exemplo, nas torcidas de futebol que propagam uma série de preconceitos sexuais e raciais em estádios de futebol ou nos CTG's que, por longos anos, não permitiram a entrada de afro-brasileiros nas suas dependências. Há uma série de instituições e grupos sociais que sustentam preconceitos sexuais e raciais em função dos quais o caráter depreciativo de termos como "macaco" e "viado" são derivados. O caráter ofensivo, no entanto, não é derivado de instituições sociais. Ele é algo que diz respeito ao estado subjetivo do sujeito que é alvo do termo depreciativo. É perfeitamente possível que uma pessoa seja depreciada por um termo e sinta-se, concomitantemente, ofendida por ele. Não é absurdo pensar, por exemplo, que um homem branco, tal como no exemplo de Hedger, sinta-se ofendido ao escutar a expressão macaco. Se esse homem não for racista, conhecer minimamente o funcionamento das injúrias raciais do português e for empático aos afro-brasileiros, é perfeitamente possível que ele sinta-se ofendido. Ele não será, no entanto, depreciado. O afro-brasileiro alvo da injúria, por sua vez, será objetivamente depreciado e, com grande probabilidade, sentir-se-á ofendido.

Para finalizar a sua análise crítica do expressivismo puro, Croom fornece cinco considerações empíricas de usos não depreciativos de injúrias. Mencionarei apenas duas aqui, pois são suficientes para entender o argumento em jogo. Se pejorativos, em especial injúrias, são expressivos, então, eles são sempre ofensivos. Ocorre, no entanto, que nem sempre eles são ofensivos, pois existem evidências empíricas de que eles são usados de modo não ofensivo. Portanto, eles não são expressivos.

O primeiro uso não ofensivo de uma injúria racial encontra-se na cultura bip-hop. De acordo com o haper Talib Kweli: "Our community has been

${ }^{28}$ HOM, 2008, p.430. 
using the word and trying to redefine the contexto of it for a long time [...] the fact of the matter is that there's a large segment of black people who grew up hearing the word intend as nothing but love"29. Essa passagem trata do uso não ofensivo ${ }^{30}$ da injúria racial nigger, talvez, a mais depreciativa em relação a afro-americanos. Como ela evidencia, a comunidade de afro-americanos usa esse termo de um modo não ofensivo. Dada a distinção que fiz entre depreciação e ofensa, o uso não depreciativo e, de certa forma, não ofensivo de uma injúria é explicado pela propriedade de apropriação. Termos pejorativos podem ser apropriados por seus alvos típicos e usados de modo não depreciativo para fins de empoderamento desses alvos típicos ${ }^{31}$. O mesmo acontece com as injúrias sexuais slut e bitch apropriadas pela comunidade LGBT da SlutWalk, tal como atesta o depoimento de um de seus fundadadores "I come from a frame of mind that language is powerful, and [that] you can also change language [...] An aim of the SlutWalk movement is to reappropiation the word "slut"'32. O mesmo fenômeno de apropriação ocorre com injúrias sexuais. Isso serve para corroborar a posição de Croom, segundo a qual, injúrias nem sempre são ofensivas tal como pretende o expressivismo puro. Creio que isso é suficiente para mostrar que a tese expressivista não procede. Penso, no entanto, que é possível sustentar uma análise semântica para pejorativos. No que se segue, apresento uma análise para macaco e viado.

\section{Uma análise semântica de "macaca" e "sapatão"}

Como mencionei anteriormente, as críticas de Croom são pertinentes. No entanto, elas não implicam a impossibilidade de fornecer uma análise semântica de termos pejorativos. Dito de outra maneira, embora as evidências apresentadas sejam relevantes, disso não se segue que pejorativos não possam ser analisados semanticamente. Por isso, o objetivo dessa seção é fornecer uma

\footnotetext{
29 KUELLI apud CROOM, p.236.

${ }^{30} \mathrm{~A}$ análise de Croom é ambígua porque ele não distingue, assim como Hedger, depreciar de ofender. Consequentemente, ele trata do caráter ofensivo das injúrias, mas, na verdade, o que ele quer discutir é o caráter depreciativo. De qualquer maneira, é perfeitamente possível pensar que uma injúria usada de modo apropriado não seja nem depreciativa nem ofensiva. Nos exemplos em discussão, as injúrias são usadas de modo não depreciativo e não ofensivo. Portanto, são usadas de modo apropriado. Em segundo lugar, deve-se observar que Croom considera a ofensa como uma característica das injúrias tal como a depreciação. Nesse sentido, ela não é um subconjunto dos pejorativos. Como um tipo de pejorativo, as ofensas possuem tanto a característica de depreciar quanto a de ofender. Pense no caso de alguém que xinga uma pessoa de retardado. Do ponto de vista objetivo (depreciativo), ela está descrevendo uma certa propriedade que supostamente o seu alvo possuiria. Do ponto de vista subjetivo (ofensivo), a pessoa xingada pode sentir-se ofendida.

${ }^{31}$ Para uma análise da propriedade de apropriação, ver Hom (2008; 2010).

32 JARVIS apud CROOM, p.237.
} 
análise semântica dos termos "macaca" e "sapatão", que deve ser lida como um contra-argumento ao expressivismo puro. Apenas para relembrar, o argumento em jogo é o seguinte: se é verdade que injúrias não são expressões com conteúdo puramente descritivo, então, elas são expressões com conteúdo puramente expressivo. É verdade que injúrias não são expressões com conteúdo puramente descritivo. Portanto, elas são expressões com conteúdo puramente expressivo. Não é o caso que injúrias são expressões com conteúdo puramente expressivo, pois elas são analisáveis semanticamente e, para serem analisáveis semanticamente, elas devem possuir conteúdo semântico. Logo, não é o caso que injúrias não são expressões com conteúdo puramente descritivo.

A análise começa com a construção da gramática $C_{R}$, a qual é dividida em dois momentos, cada um deles subdividido em outros dois ${ }^{33}$. Restringirei esses momentos aos elementos constitutivos das frases "Rafaela é um sapatão" e "Rafaela é uma macaca", pois aplicarei $C_{R}$ a essas frases apenas. Isso significa que as regras sintáticas e semânticas de $C_{R}$ cobrirão apenas os elementos dessas frases. O primeiro momento consiste na construção da sintaxe da gramática. Para construí-la são necessários dois passos. O primeiro é a estipulação do léxico, ou seja, a enumeração de cada um dos componentes de $C_{R}$. O segundo passo é a formulação das regras sintáticas que me permitem dizer quando as estruturas sintagmáticas são bem formadas. $O$ segundo momento, a construção da semântica da gramática, também subdivide-se em dois passos. $\mathrm{O}$ primeiro é a estipulação do significado lexical, ou seja, a determinação do significado de cada um dos membros mais básicos do léxico, como, por exemplo, o significado de um verbo transitivo. Finalmente, o segundo passo é a formulação das condições de verdade das frases. Como o universo do discurso em questão é composto por "Rafaela é um sapatão" e "Rafaela é uma macaca”, $C_{R}$ ficará enxuta. Dado esse universo do discurso, a sintaxe de $C_{R}$ será:
A) Léxico de $C_{R}$

\section{$\left.1^{\circ}\right)$ Regras de inserção lexical:}

As regras de inserção lexical servem para introduzir os elementos mínimos da gramática.

a) $n c \rightarrow$ \{homem, mulher, cadeira, ... $\}$

Um nome comum é um elemento encontrável na lista ...

b) $n p \rightarrow\{$ Carlos, Maria, Paula, ... $\}$

Um nome próprio é um elemento encontrável na lista ...

33 Ver em: CHIERCHIA, 2003, p.84-85. 
c) $v l \rightarrow\{$ ser, esta, ficar, ... $\}$

Um verbo de ligação é um elemento encontrável na lista ...

d) $\operatorname{det} \rightarrow\{$ a, o, as, os, um, uma, ... $\}$

Um determinante é um elemento encontrável na lista ...

\section{$\left.2^{\circ}\right)$ Regras sintáticas:}

As regras sintáticas permitem dizer se uma estrutura sintagmática é bem formada ou não. Para o domínio de $C_{R}$, necessito das seguintes regras ${ }^{34}$ :

a) $S \rightarrow S N S V$ : uma sentença pode ser constituída por um sintagma nominal e um sintagma verbal.

b) $S N \rightarrow n p:$ um sintagma nominal pode ser constituído por um nome próprio.

c) $S N \rightarrow$ det: um sintagma nominal pode ser constituído por um determinante.

d) $S N \rightarrow n c:$ um sintagma nominal pode ser constituído por um nome comum.

e) $S V \rightarrow v l S N n c$ um sintagma verbal pode ser constituído por um verbo de ligação, um sintagma nominal e um nome comum.

B) SEMÂNTICA de $C_{R}$

$\left.1^{\circ}\right)$ Significado lexical ou valor semântico das palavras

O significado lexical das palavras é a fixação do significado de cada elemento básico do léxico. Isso é feito da seguinte forma:

a) Valor semântico de um $n p$ :

Val ( $x$, "Maria") sse $x=$ Maria

Val ( $x$, "Paulo") sse $x=$ Paulo

etc...

b) Valor semântico de um $n c$ :

Val $(x$, "maçã") sse xé uma maçã

$\operatorname{Val}(x$, "bicicleta") sse $x$ é uma bicicleta

etc...

c) valor semântico de um det:

$\operatorname{Val}(x$, "o") sse, em uma estrutura [SN $\rightarrow$ det $n c], x$ é aquele ou aquilo que satisfaz o $n p, n c$ ou pron que segue "o" no $S N$ (por exemplo, $\left[[S N]_{d e t} \mathrm{O}\right]$ [nhomem] é fumante]])

${ }^{34}$ Deve ser possível expandir as regras e a gramática como um todo para analisar outros tipos de frases. 
Val ( $x$, "uma") sse, em uma estrutura $[S N \rightarrow \operatorname{det} n c], x$ é uma instância do $n c$ que segue "uma" no $S N$ (por exemplo, [[SN $\left.{ }_{d d e t} \mathrm{Uma}\right]\left[{ }_{n}\right.$ mulher] é fumante]])

Val ( $x$, “um") sse, em uma estrutura [ $S N \rightarrow$ det $n c], x$ é uma instância do $n c$ que segue "um" no $S N$ (por exemplo, [[SN $\left[{ }_{d e t} \mathrm{Um}\right]\left[{ }_{n}\right.$ homem] é fumante]])

etc ...

d) Valor semântico de um $v$ :

$\operatorname{Val}(x$, "é") $=\varnothing$

$\operatorname{Val}(x$, "permanece") $=\varnothing$

etc...

$\left.2^{\circ}\right)$ Condições de verdade

O último passo de $C_{R}$ é a formulação das condições de verdade das frases. Nessa parte, há um elemento altamente contextual. Para evitar o uso de exemplos hipotéticos, que também podem ser usados sem nenhum prejuízo analítico, usarei casos concretos de racismo e lesbofobia divulgados na mídia brasileira. Nesse sentido, talvez o caso da judoca brasileira, Rafaela Silva, seja o mais recente e paradigmático ${ }^{35}$. Quando foi desclassificada na olimpíada de Londres, em 2012, Rafaela foi alvo de vários ataques racistas e, hoje, após a sua conquista da medalha de ouro na olimpíada de 2016, no Brasil, tornou-se público que Rafaela mantém um relacionamento homoafetivo há três anos. Rafaela, portanto, é um exemplo típico de milhares de brasileiros que são pobres, negros, homossexuais e vítimas de preconceito.

Considere as frases "Rafaela é uma macaca" e "Rafaela é um sapatão", cujas análises sintáticas são:

(8) Rafaela é uma macaca.

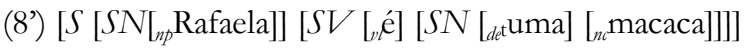

(9) Rafaela é um sapatão

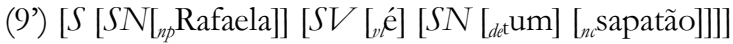

O contexto de enunciação de (8) e (9) tanto pode ser as redes sociais quanto o estádio no qual a atleta foi depreciada após ser desclassificada das olimpíadas de 2012 em Londres. Não se trata, portanto, de um exemplo hipotético, embora também seja possível usá-los sem nenhum prejuízo para a

\footnotetext{
35 Existem vários casos. Escolhi este, pois ele é muito recente. Outro caso que repercutiu muito foi do goleiro Aranha dos Santos. O modelo poderia ser aplicado ao caso do Aranha. O leitor encontrará várias fontes sobre o caso de Rafaela. Uma delas é acessível em: <http://www.geledes.org.br/rafaela-omacaco-que-tinha-que-estar-na-jaula-hoje-e-campeao/>.
} 
análise. Nesse caso, para que (8) e (9) tenham sentido é necessário que as condições estabelecidas pelo esquema $T^{36}$ realizem-se:

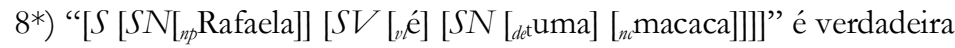
sse Rafaela é uma macaca.

$\mathrm{e}$

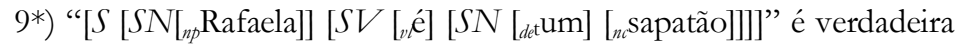
sse Rafaela é um sapatão.

Observe que $\left(8^{*}\right)$ e $\left(9^{*}\right)$ expressam que as frases que estão entre aspas (frase da linguagem objeto) são verdadeiras se e somente se as frases que estão sem aspas (frases da metalinguagem) são verdadeiras e vice-versa. O esquema, portanto, tem uma leitura de mão dupla, vai da linguagem objeto para a metalinguagem e desta para aquela. Assim, se pressuponho os dois casos em que a equivalência é verdadeira, tomo apenas o caso em que a meta-sentença e a frase objeto são verdadeiras, pois, no outro caso, ambas são falsas e tenho um caso de verdade trivial. Os outros casos são descartados porque a equivalência é falsa. Logo, no único caso em questão, para que as sentenças da linguagem objeto sejam verdadeiras, as condições de significado estabelecidas anteriormente devem ser realizadas. Nesse caso, $\left(8^{*}\right)$ e $\left(9^{*}\right)$ serão verdadeiras e as frases objetos terão sentido. De acordo com as condições de significado, para que (8) seja verdadeira é necessário que:

8a) Val ( $x$, "Rafaela") sse $x=$ Rafaela

8b) $\operatorname{Val}(x$, "é") $=\varnothing$

8c) Val ( $x$, "uma") sse, em uma estrutura $[S N \rightarrow$ det $n c]$, x é uma instância do $n c$ que segue "uma" no $S N$.

$8 d) \operatorname{Val}(x$, "macaca") sse $x=$ macaca

No contexto em que (8) foi usada, ela é notoriamente, falsa. Por quê? Porque ela expressa que a judoca Rafaela é uma macaca. Para demonstrar a falsidade dessa frase, basta recorrer à descrição que um primatologista faz dos macacos ou a fotos de macacos e compará-las com a judoca. Evidentemente, nem a descrição nem as fotos coincidirão com a judoca, uma vez que ela é um Homini do gênero Homo e o macaco um Homini do gênero Pan, caso os depreciadores estivessem pensando em um chipanzé. Nesse caso, portanto, a condição (d) não é satisfeita. Logo, a frase objeto é falsa. Mas é possível que a mesma frase objeto seja verdadeira e, consequentemente, a equivalência também? Creio que sim. Pense, por exemplo, na seguinte situação. Paulo e Fernanda combinaram de fazer um passeio no zoológico da cidade de Paulo. Instantes antes de eles saírem, Paulo pergunta para Fernanda se ela já viu um

${ }^{36}$ Isto foi proposto por LARSON \& SEGAL (1995) e LUDLOW (1999, p.31-32). 
macaco ao que ela responde negativamente. Assim, Paulo observa que será legal, pois ela conhecerá Rafaela. Fernanda pergunta para Paulo quem ou o que é Rafaela. Imediatamente, Paulo responde que "Rafaela é uma macaca". Nesse contexto, é evidente que o nome comum não está sendo atribuído a um primata do gênero Homini, mas a um primata do gênero Pan. Logo, a frase objeto é verdadeira, assim como a equivalência. Mas por que a frase é depreciativa no primeiro contexto e não é depreciativa no segundo contexto? Respondo essa pergunta após analisar "Rafaela é sapatão".

No caso de "Rafaela é um sapatão", é necessário que a frase objeto que ocorre em $\left(9^{*}\right)$ seja verdadeira a fim de que a equivalência também o seja e, consequentemente, a frase objeto tenha sentido. Para tanto, as condições de significado de (9) devem ser satisfeitas, ou seja:

9a) $\operatorname{Val}(x$, "Rafaela") sse $x=$ Rafaela

9b) $\operatorname{Val}(x$, "é") $=\varnothing$

9c) Val ( $x$, “um”) sse, em uma estrutura [SN $\rightarrow$ det $n c], \mathrm{x}$ é uma instância do nc que segue "um" no $S N$.

9d) Val ( $x$, "sapatão") sse $x=$ sapatão

Em um sentido literal "sapatão" quer dizer "sapato grande” e não tem sentido depreciativo. Embora soe estranho, posso dizer, por exemplo, que determinada marca de calçado, a Rafaela, é um sapatão. Nesse caso, o termo tem sentido literal e não é depreciativo, pois significa que a marca de sapato é de grande qualidade, muito bonita ou é muito grande. É claro que, em contextos desse tipo, a frase pode ser verdadeira, especificados critérios de beleza, qualidade e tamanho de sapatos. No caso da judoca brasileira, porém, a expressão e a frase como um todo assumem um sentido depreciativo, pois ela é usada para tipificá-la em função de sua orientação sexual ou, mais especificamente, para tipificá-la em função de manter um relacionamento homo afetivo com outra mulher. Nesse caso específico, não há nada no mundo que corresponda ou seja significado pelo termo "sapatão", exceto uma pseudopropriedade de Rafaela. Consequentemente, a frase é falsa e tem um sentido depreciativo. A questão que permanece em aberto, portanto, é por que "macaca" e "sapatão", nas suas ocorrências depreciativas têm essa natureza? Dito de outra forma, por que elas têm sentido depreciativo?

Creio que a melhor explicação para o caráter depreciativo de injúrias foi fornecida por Hom (2008). De acordo com o externalismo combinatorial, o conteúdo depreciativo de uma injúria racial é determinado por uma fonte externa ao termo ${ }^{37}$. Essa fonte externa é formada pelas instituições sociais do

${ }^{37} \mathrm{HOM}, 2008$, p.430. 
racismo, isto é, as ideologias e o conjunto de práticas sociais ${ }^{38}$. Por exemplo, as crenças que parte da população branca brasileira nutre acerca dos afrobrasileiros e as práticas de rejeição e exclusão de certos âmbitos sociais servem como exemplo do que Hom entende por instituições sociais do racismo. Dizer que afro-brasileiros são intelectualmente inferiores e, por isso, não merecem ascender socialmente ou não merecem ter acesso ao ensino superior é um típico exemplo de crença negativa para com afro-brasileiros, assim como de uma prática histórica de exclusão social. Se, por exemplo, mulato é usado como um termo depreciativo ${ }^{39}$, o seu significado é derivado e sustentado pelas instituições sociais do racismo. Analogamente, se macaco é usado depreciativamente, o seu significado depreciativo é derivado e sustentado pelas instituições sociais do racismo. As injúrias dirigidas à judoca Rafaela, portanto, adquirem lastro depreciativo em função disso. Não vejo maiores dificuldades de expandir isso para injúrias sexuais. Assim, no caso do termo "sapatão", o seu significado depreciativo é derivado e sustentado pelas instituições sociais da lesbofobia. Logo, os termos "macaca" e "sapatão" expressam propriedades negativas construídas socialmente, uma vez que estão conectadas externa e causalmente com as instituições sociais racistas e lesbofóbicas.

\section{Conclusão}

Como mostrei anteriormente, o argumento expressivista puro sustenta que se é verdade que injúrias não são expressões com conteúdo puramente descritivo, então, elas são expressões com conteúdo puramente expressivo. É verdade que injúrias não são expressões com conteúdo puramente descritivo. Portanto, elas são expressões com conteúdo puramente expressivo. A pretensão do expressivismo puro é descartar uma análise semântica de pejorativos, em particular de injúrias raciais e sexuais. No entanto, se a análise semântica aqui proposta para "macaca" e "sapatão" está correta, então, posso negar o consequente do argumento expressivista com base nessa análise. Consequentemente, o contra-argumento assume a seguinte constituição: se é verdade que injúrias não são expressões com conteúdo puramente descritivo, então, elas são expressões com conteúdo puramente expressivo. É verdade que injúrias não são expressões com conteúdo

38 HOM, 2008, p.430-431.

39 "Mulato" é um típico termo depreciativo para com afro-brasileiros. Há uma literatura detalhada sobre 0 surgimento do termo mulato. Para tanto, ver Lara (2012), Mattos (2006 e 2013) e Alencastro (2000). Deve-se observar que uma característica da força depreciativa é que ela pode sofrer mudanças ao longo dos tempos de acordo com as dinâmicas sociais. Nesse caso, mulato é um bom exemplo, pois é um termo que surgiu com uma força depreciativa forte, mas, nos dias de hoje, foi amplamente incorporado na cultura brasileira sem ou quase sem força depreciativa. 
puramente descritivo. Portanto, elas são expressões com conteúdo puramente expressivo. Não é o caso que injúrias são expressões com conteúdo puramente expressivo, pois elas são analisáveis semanticamente e, para serem analisáveis semanticamente, elas devem possuir conteúdo semântico. Logo, não é o caso que injúrias não são expressões com conteúdo puramente descritivo.

Creio que o modelo de satisfação pode ser estendido para os demais tipos de pejorativos sem maiores complicações. Uma vantagem que ele possui é deixar em aberto a adoção de um melhor modelo explicativo para o caráter depreciativo dos pejorativos. É claro, porém, que explicações ao estilo expressivista puro não são compatíveis com ele, dadas as razões apresentadas aqui. Teorias ao estilo externalista combinatorial, porém, são perfeitamente compatíveis com o modelo semântico proposto. Para finalizar, eu diria que a resposta para a pergunta que dá título a este artigo é que o expressivismo puro não funciona para injúrias raciais e sexuais porque ele tem uma concepção equivocada do significado desses pejorativos. Diferentemente do que pretende o expressivismo puro, injúrias raciais e sexuais são analisáveis semanticamente.

\section{Referências}

ALENCASTRO, Luiz Felipe. O trato dos viventes: formação do Brasil no atlântico sul. São Paulo: Companhia das Letras, 2000.

ANDERSON, L.; LEPORE, E. “Slurring words”. In: Nous, n.47, p.25-48, 2013.

AYER, A. J. Language, Truth, and Logic. New York: Dover, 1936.

BOISVERT, D. “Expressivism-assertivism”. In: Pacific Philosophical Quarterly, n.89, p.169-203, 2008.

CROOM, A. “Slurs”. In: Language Sciences, n.33, p.343-358, 2011.

. "The semantics of slurs: a refutation of pure expressivism". In:

Language Sciences, n.41, p.227-242, 2012.

. "Remarks on 'The semantics of racial slurs"'. In: Linguistic and

Philosophical Investigations, n.13, p.11-32, 2014.

GUTZMANN, D. "Expressive modifiers and mixed expressives". In:

BONAMI, O.; HOFHERR, P. (eds.). Empirical Issues in Syntax and Semantics, v.

7. Colloque de Syntaxe et Sematique de Paris: Paris, p.123-141, 2011.

HARE, R. M. The Language of Morals. Oxford: Oxford University Press, 1952.

HAY, R. "Hybrid expressivism and the analogy between pejoratives and moral language". In: European Journal of Philosophy, v.21, p.450-474, 2011. 
HEDGER, J. “The semantics of racial slurs: using Kaplan's framework to provide a theory of the meaning of derogatory epithets". In: Linguistic and Philosophical Investigations, n.11, p.74-84, 2012.

HOM, Christopher. "A puzzle about pejoratives". In: Philosophical Stud, n.159, p.383-405, 2012.

. “Pejoratives". In: Philosophy Compass. v.5, n.2, p.164-185, 2010.

."The semantics of racial epithets". In: The Journal of Philosophy, v.105, n.8, p.416-440, 2008.

KAPLAN, D. The Meaning of Ouch and Oops: explorations in the Theory of Meaning as Use (unpublished manuscript). University of California, Los Angeles, 1999.

KRATZER, A. Beyond ouch and oops: how descriptive and expressive meaning interact. Cornell Conference on Theories of Context Dependency (26March), Cornell University, 1999.

LARA, Sílvia Hunold. "No jogo das cores: liberdade e racialização das relações sociais na América portuguesa setecentista”. In: XAVIER, Regina Célia Lima. Escravidão e liberdade: temas, problemas e perspectivas de análise. São Paulo: Alameda, 2012, p.71-93.

LARSON, Richard; SEGAL, Gabriel. Knowledge of meaning: an introduction to semantic theory. Cambridge: MIT, 1995.

LUDLOW, P. Semantics, tense, and time: an essay in the metaphysics of natural language. CAMBRIDGE: MIT, 1999.

MATTOS, Hebe. "'Pretos' and 'Pardos' between the cross and the sword: racial categories in seventeenth century Brazil". In: Revista Europa de Estudios Latinoamericanos y del Caribe, n.80, p.43-55, 2006.

. Das cores do silêncio. Campinas: Editora da Unicamp, 2013.

McCREADY, E. "Varieties of conventional implicature". In: Semantics and Pragmatics, n.3, p.1-57, 2010.

POTTS, C. "Expressive content as conventional implicature". In:

KADOWAKI, M.; KAWAHARA, S. (eds.). Proceedings of the North East

Linguistics Society, v.33. GLSA, Amherst, p.303-322, 2003.

2005.

. The Logic of Conventional Implicature. Oxford: Oxford University Press, . “The expressive dimension”. In: Theoretical Linguistics, v.33, p.165-197, 2007. 
. "Conventional implicature and expressive content". In:

MAIENBORN, C.; VON HEUSINGER, K.; PORTNER, P. (eds.). Semantics: an international handbook of natural language meaning, v. 3. Berlin: Mouton de Gruyter, p.2516-2536, 2012.

SCHROEDER, M. Being for evaluating the semantic program of expressivism. Oxford: Oxford University Press, 2008.

STEVENSON, C. L. Facts and V alues. Westport: Greenwood Press, 1963.

WHITING, D. "It's not what you said, it's the way you said it: slurs and conventional implicatures”. In: Analytic Philosophy, v.54, n.3, p.364-377, 2013. . "Inferentialism, representationalism and derogatory words". In: International Journal of Philosophical Studies, v.15, p.191-205, 2007.

WILLIAMSON, T. "Reference, inference and the semantics of pejoratives". In: ALMONG, J., LEONARDI, P. (eds.). The Philosophy of David Kaplan.

Oxford: Oxford University Press, 2009. 